\title{
Selection for contrasting seed tocopherol content in sunflower seeds
}

\author{
L. VELASCO*, L. DEL MORAL, B. PÉREZ-VICH AND J. M. FERNÁNDEZ-MARTÍNEZ \\ Institute for Sustainable Agriculture (CSIC), Alameda del Obispo s/n, 14004 Córdoba, Spain \\ (Revised MS received 2 November 2009; Accepted 10 November 2009; First published online 13 January 2010)
}

\begin{abstract}
SUMMARY
Sunflower oil, with more than 0.9 of tocopherols in the alpha-tocopherol form, supplies more vitamin $\mathrm{E}$ than any other vegetable oil. Thus far, no breeding to increase vitamin $\mathrm{E}$ levels in sunflower seeds has been conducted. The objective of the present research was to develop sunflower lines with high and low total seed tocopherol content through evaluation and subsequent selection of a large germplasm collection (952 sunflower entries). A range of variation from 119 to $491 \mathrm{mg} / \mathrm{kg}$ was found. Selection conducted from $\mathrm{S}_{1}$ to $\mathrm{S}_{4}$ plant generations allowed the isolation of line IAST-413, with an increased tocopherol content of $467 \mathrm{mg} / \mathrm{kg}$ compared to $251 \mathrm{mg} / \mathrm{kg}$ in the control line HA89, and line IAST-522, with a reduced tocopherol content of $73 \mathrm{mg} / \mathrm{kg}$. Another accession with potentially high tocopherol content, but completely self-incompatible, was crossed to the line HA89 followed by plant-to-row selection up to the $F_{5}$ plant generation; it averaged $463 \mathrm{mg} / \mathrm{kg}$ compared to $240 \mathrm{mg} / \mathrm{kg}$ in HA89. Two field experiments carried out at Córdoba in southern Spain in 2006 and 2007 with different sowing dates confirmed that the increased tocopherol content in the selected lines was consistently expressed across environments.
\end{abstract}

\section{INTRODUCTION}

Vitamin $\mathrm{E}$ is a family of fat-soluble antioxidants that protect cellular membrane lipids against oxidative damage, which has been associated with a decreased risk of developing some forms of cancer, cardiovascular diseases and degenerative processes linked to disease (Packer \& Obermüller-Jevic 2002). The main naturally occurring compounds with vitamin $\mathrm{E}$ activity are tocopherols and tocotrienols. Tocopherols occur ubiquitously in plant tissues, with the highest concentrations being found in seeds. There are four tocopherols, alpha-, beta-, gamma- and delta-tocopherol, which differ in their vitamin $\mathrm{E}$ activities. Alpha-tocopherol exerts the highest vitamin E activity in animals (Pongracz et al. 1995). There is a large body of medical evidence pointing to the benefits for human health associated with daily, moderate, vitamin E supplementation (Bramley et al. 2000).

Gamma-tocopherol, with only one-tenth the vitamin-E activity of alpha-tocopherol (Pongracz et al. 1995), is the predominant tocopherol derivative in

* To whom all correspondence should be addressed. Email: lvelasco@ias.csic.es most oilseeds (Padley et al. 1994). Sunflower, with more than 0.9 of tocopherols in the alpha-tocopherol form, represents a remarkable exception. The high vitamin E content of sunflower oil is being used by some manufacturers as a claim to attract consumers, even through fortification of the oil with either natural or synthetic alpha-tocopherol. Several brands of sunflower oil fortified with alpha-tocopherol are currently being marketed in Spain. Sunflower cultivars with increased concentrations of alpha-tocopherol in the seeds would produce oils with naturally enhanced vitamin $\mathrm{E}$ value.

The tocopherol content in the extracted seed oil is the result of several factors, the most important being the tocopherol content in the seeds, the oil content in the seeds, the oil extraction system and the loss of tocopherols during oil refining (Tasan \& Demirci 2005). Sunflower oil is mainly made up of triacylglycerols (Åppelqvist 1989). Triacylglycerols and tocopherols are accumulated separately in the cells of sunflower seeds through different biosynthetic pathways. While storage triacylglycerols are deposited in characteristic structures called oil bodies or oleosomes (Slack et al. 1980), tocopherols are components of membranes (Hofius \& Sonnewald 
2003). Because tocopherols are fat-soluble compounds, they become part of the extracted oil during oil extraction. Accordingly, the optimal breeding strategy to identify genetic sources of high tocopherol content is to select for this trait regardless of the seed oil content. Both traits must be combined later because there is evidence that they are not correlated (Velasco et al. 2002).

Unrefined sunflower oils have average tocopherol contents around $700 \mathrm{mg} / \mathrm{kg}$ (Padley et al. 1994). Most of the studies reporting variation for seed tocopherol content in sunflower cultivars or germplasm have been based on analyses of extracted oils (Dolde et al. 1999; Alpaslan \& Gündüz 2000; Nolasco et al. 2004). The analysis of tocopherol content in the extracted oil does not differentiate characters such as seed oil content or seed tocopherol content, and therefore does not provide information on genetic differences for the efficiency of the tocopherol biosynthetic pathway. Velasco et al. (2002) reported a range of variation for seed tocopherol content from 314 to $1024 \mathrm{mg} / \mathrm{kg}$ in evaluation of 36 sunflower hybrids grown over 13 locations. The tocopherol content of sunflower seeds is affected by the genotype and the environment, although the limited number of studies conducted to date have concluded that the factors have different relative effects (Marquard 1990; Alpaslan \& Gündüz 2000; Velasco et al. 2002). No breeding research has been conducted to develop sunflower germplasm with high tocopherol content. In rapeseed, lines with high and low total tocopherol content were selected (Goffman \& Becker 2001), and provided the basis for genetic and molecular studies on tocopherol accumulation in this crop (Marwede et al. 2005).

The objectives of the present research were to develop sunflower lines with high and low total tocopherol content in the seeds through evaluation of a large germplasm collection and through subsequent selection to evaluate the environmental stability of total tocopherol content in selected lines.

\section{MATERIALS AND METHODS}

\section{Germplasm evaluation and selection}

A germplasm collection of 952 sunflower (Helianthus annuus L.) entries was analysed for total seed tocopherol content as described below. The collection included 631 germplasm accessions provided by the North Central Regional Plant Introduction Station of the US Department of Agriculture (USDA) as well as 321 breeding lines and cultivars maintained for different research programmes at the Institute for Sustainable Agriculture at Córdoba, Spain. Total tocopherol content was measured on six seeds per accession. Twenty eight accessions with low and high total tocopherol content were selected; $48 \mathrm{~S}_{0}$ seeds from each of these were germinated and plants grown in the field in 2000. Single plants were bagged before flowering to ensure self-fertilization and they were harvested by hand at maturity. Six randomly selected $\mathrm{S}_{1}$ seeds from each individual plant were used for total tocopherol content analysis as described below. Selection following a head to row scheme was continued until the $\mathrm{S}_{4: 5}$ generation. Plants were grown in rows $5 \mathrm{~m}$ long with $1 \mathrm{~m}$ spacing between rows. Plants of the inbred line HA89, with wild-type total tocopherol content, and the $F_{1}$ hybrid Xistral, identified in previous research as having one of the highest tocopherol contents amongst commercial hybrids cultivated in Spain (Velasco et al. 2002) were used as controls in all the evaluations. The best $\mathrm{S}_{4: 5}$ families having either high or low tocopherol content were selected and their seeds were pooled to constitute the selected lines.

\section{Evaluation under a range of environments}

Two field experiments based on periodical sowings were conducted in 2006 and 2007 to evaluate the expression of total tocopherol content in the selected lines IAST-306 and IAST-413, with increased tocopherol content, and IAST-522, with reduced tocopherol content, as well as the line HA89 with standard tocopherol content (control). The field experiment in 2006 consisted of six sowing dates: 13 and 27 February, 13 and 27 March and 10 and 24 April. The field experiment in 2007 consisted of eight sowing dates: 19 February, 5 and 26 March, 9 and 23 April, 7 and 28 May and 11 June. In both years, trials were located at the experimental farm of the Institute for Sustainable Agriculture, Córdoba $\left(37^{\circ} 51^{\prime} 51^{\prime \prime} \mathrm{N}\right.$; $4^{\circ} 47^{\prime} 23^{\prime \prime} \mathrm{W} ; 91 \mathrm{~m}$ asl). Each sowing date consisted of 36 plants of each line arranged in a completely randomized design. Seeds of each line were germinated on moistened filter paper, grown in small pots in a growth chamber for 15 days and then transplanted to the field in rows $5 \mathrm{~m}$ long with $1 \mathrm{~m}$ between rows and $0.2 \mathrm{~m}$ between plants in the row. Plants of HA 89 were grown as plot borders. The plants were harvested individually at maturity. In some cases, the occurrence of a poor seed set associated with self-incompatibility resulted in a considerable reduction in the number of plants per line that produced enough seeds for tocopherol analysis. To keep the results representative, those cases in which the number of plants analysed per sowing date and line was below 12 were discarded.

\section{Analysis of total seed tocopherol content}

Six randomly selected achenes from each accession or individual plant were dehusked, weighed and crushed as finely as possible with a stainless steel rod. Tocopherol content was determined by highperformance liquid chromatography (HPLC) as described by Thies (1997), using a fluorescence detector 


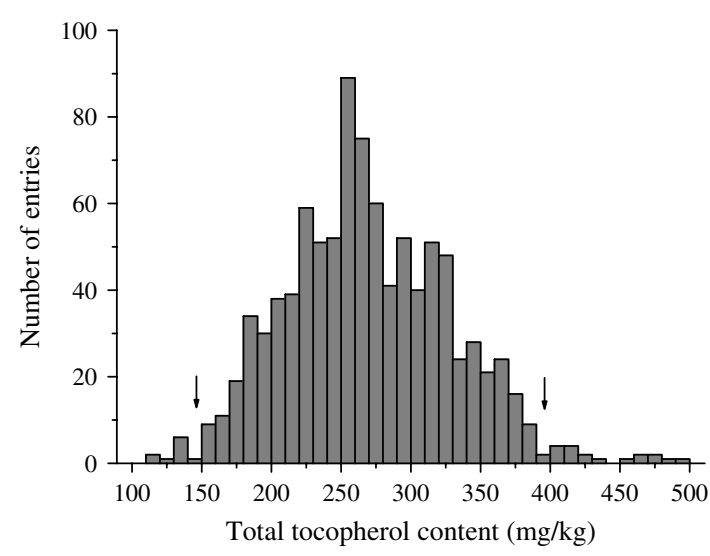

Fig. 1. Total tocopherol content in $S_{0}$ seeds of 952 sunflower entries. Selection cut-offs for low and high tocopherol content are indicated by arrows.

at $295 \mathrm{~nm}$ excitation and $330 \mathrm{~nm}$ emission and isooctane/tert-butylmethylether $(94: 6)$ as eluent at an isocratic flow rate of $0.7 \mathrm{ml} / \mathrm{min}$. Chromatographic separation of the tocopherols was performed on a LiChrospher 100 diol column (internal dimensions $250 \times 3 \mathrm{~mm}$ ) with $5 \mu \mathrm{m}$ spherical particles, connected to a silica guard column (LiChrospher Si 60, internal dimensions $5 \times 4 \mathrm{~mm}$ ). Quantitative determination of tocopherols was carried out using external calibration curves. Total tocopherol content was calculated as the sum of alpha-, beta- and gamma-tocopherol contents. Total tocopherol content was expressed as $\mathrm{mg} / \mathrm{kg}$ seed.

\section{RESULTS \\ Germplasm evaluation and selection}

The average total tocopherol content in the set of 952 germplasm accessions, \pm s.D., was $271 \pm 62 \cdot 1 \mathrm{mg} / \mathrm{kg}$, showing a range of variation from 119 to $491 \mathrm{mg} / \mathrm{kg}$. Alpha-tocopherol was the predominant tocopherol derivative, accounting for more than 0.9 of the total tocopherols in the seeds in most of the accessions, except for PI 307937, which had 0.78 alpha- and 0.22 beta-tocopherol and CO-77-256, which had 0.77 alpha- and $0 \cdot 23$ gamma-tocopherol. Selection cut-offs for low and high total tocopherol content were established at 145 and $400 \mathrm{mg} / \mathrm{kg}$, respectively, based on the distribution of the trait in the germplasm collection (Fig. 1). This resulted in 10 accessions being selected for low tocopherol content and 18 accessions being selected for high tocopherol content, all with alpha-tocopherol as the predominant form.

Total tocopherol content at the $\mathrm{S}_{0}$ plant level $\left(\mathrm{S}_{1}\right.$ seeds averaged) ranged from 60 to $564 \mathrm{mg} / \mathrm{kg}$ for the 28 lines selected. The extremes of variation corresponded to two accessions: IAS-522, which showed
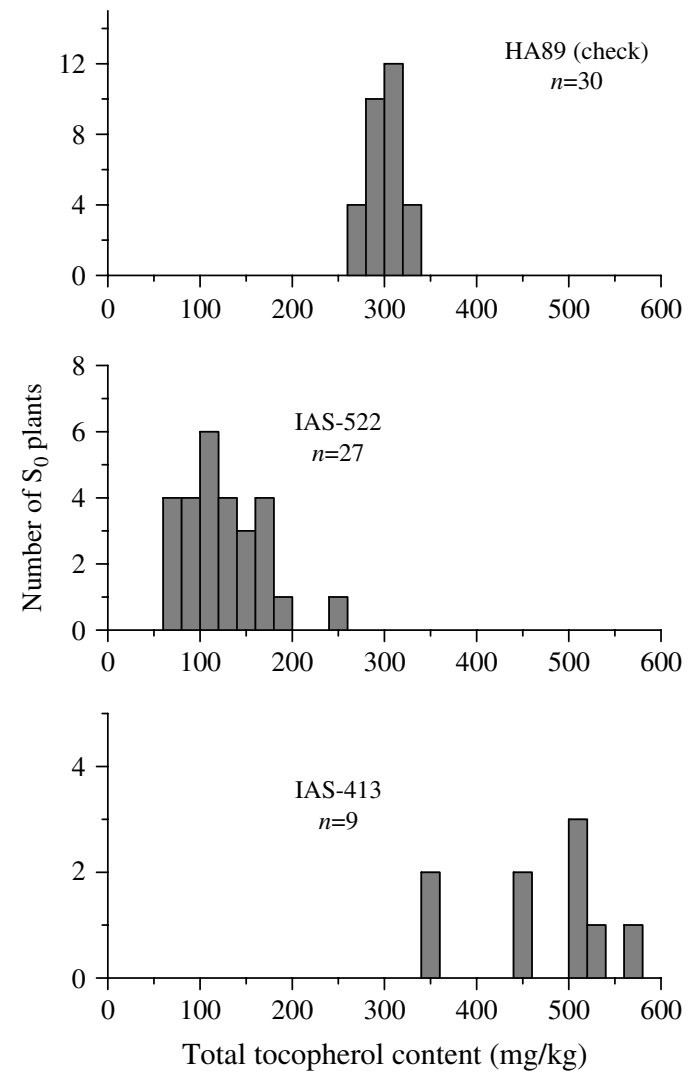

Fig. 2. Total tocopherol content in the check line HA89 and $\mathrm{S}_{0}$ plants $\left(\mathrm{S}_{1}\right.$ seeds averaged) of the accessions IAS-522 and IAS-413.

$60-244 \mathrm{mg} / \mathrm{kg}$, and IAS-413, with a range of $342-564 \mathrm{mg} / \mathrm{kg}$ (Fig. 2). The number of plants of IAS413 was very low due to low seed germination. Plants of the control line HA89 showed total seed tocopherol contents from 269 to $340 \mathrm{mg} / \mathrm{kg}$. The accession IAS-522 corresponded to a selection for broomrape (Orobanche) race E resistance conducted within a collection of old Spanish cultivars, but the pedigree of the germplasm was unknown. The accession IAS413 corresponded to a selection from the Russian variety Peredovik conducted in Spain in the early 1980s (J. M. Fernández-Martínez, personal communication).

All the plants of accession PI 256334 from the USDA-ARS genebank, which showed the highest total tocopherol content in the initial evaluation of the germplasm collection, failed to produce seed due to complete self-incompatibility. In order to recover the trait, plants of PI 256334 were grown the following season and crossed to HA89, which is characterized by high self-compatibility. 


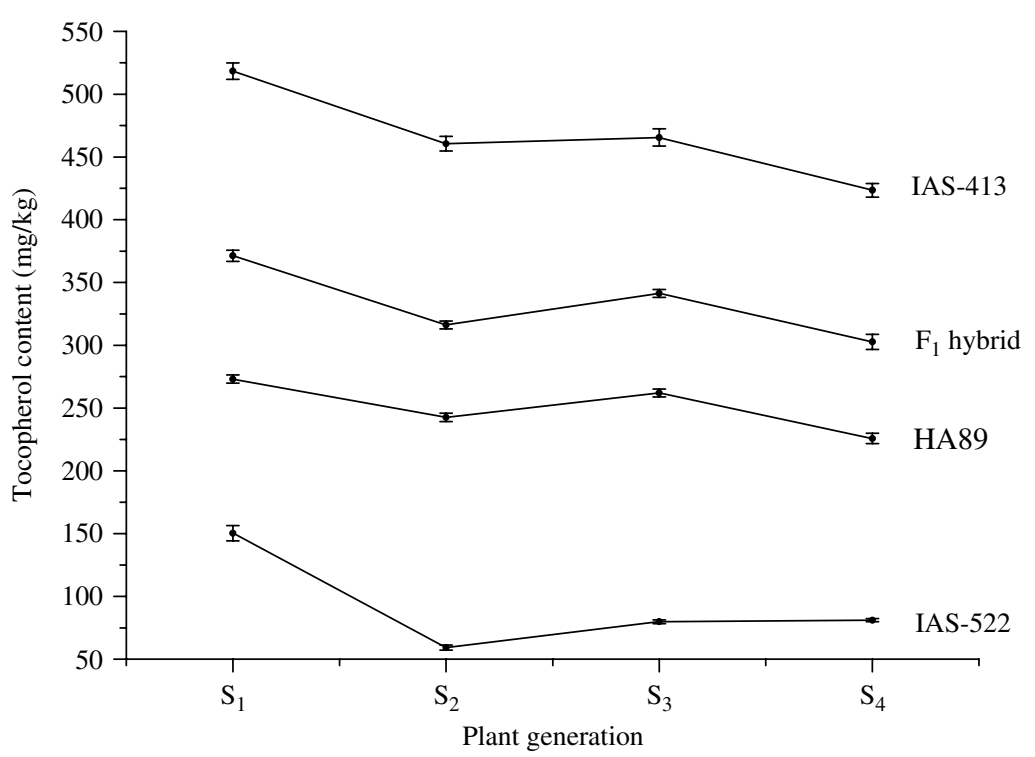

Fig. 3. Total seed tocopherol content in the plant generations $S_{1}\left(S_{2}\right.$ seeds averaged) through $S_{4}\left(S_{5}\right.$ seeds averaged) of selections from the germplasm accessions IAS-413, selected for high tocopherol content and IAS-522, selected for low tocopherol content. The line HA89 and the $\mathrm{F}_{\mathbf{1}}$ hybrid 'Xistral' were used as checks.

Selection conducted from $\mathrm{S}_{1}$ to $\mathrm{S}_{4}$ plant generations is summarized in Fig. 3. Selections from IAS-413 already showed a high total seed tocopherol content and low S.E.M. $(518 \pm 6 \cdot 6 \mathrm{mg} / \mathrm{kg})$ in the $\mathrm{S}_{1}$ generation, compared to $273 \pm 3 \cdot 3 \mathrm{mg} / \mathrm{kg}$ in the inbred line HA89 and $371 \pm 4.4 \mathrm{mg} / \mathrm{kg}$ in the commercial $F_{1}$ hybrid Xistral, both of which were used as controls. The differences for total seed tocopherol content between IAS-413 and both controls were maintained in subsequent generations (Fig. 3). The overall tocopherol content of IAS-413 selections in the four generations was $467 \mathrm{mg} / \mathrm{kg}$, compared to $251 \mathrm{mg} / \mathrm{kg}$ in HA89 and $337 \mathrm{mg} / \mathrm{kg}$ in Xistral. Selections from IAS-522 showed similar segregation in the $S_{1}$ generation for seed tocopherol content to the previous generation, from 70 to $266 \mathrm{mg} / \mathrm{kg}$. No additional segregation was observed in the $S_{2}$ to $S_{4}$ generations (Fig. 3), which showed an average tocopherol content of $73 \mathrm{mg} / \mathrm{kg}$. The lines IAST-413 and IAST-522 were constituted from $\mathrm{S}_{5}$ seeds of IAS-413 and IAS-522 selections, respectively.

The cross between plants of the accession PI 256334, with high total seed tocopherol content but highly self-incompatible, with plants of the inbred line HA89 produced an $\mathrm{F}_{2}$ population showing wide segregation for total tocopherol content, from 125 to $582 \mathrm{mg} / \mathrm{kg}$ (Fig. 4). Selection for high total tocopherol content was conducted from the $F_{2}$ to $F_{4}$ plant generations, which resulted in an $\mathrm{F}_{5}$ plant generation with high average total tocopherol content and low standard error $(463 \pm 5.6 \mathrm{mg} / \mathrm{kg}$; Fig. 4). Plants of HA89 and IAS-413 grown in the same environment averaged $239 \pm 2.6$ and $431 \pm 5.1 \mathrm{mg} / \mathrm{kg}$. The line IAST-306 was constituted from $F_{6}$ seeds of the selections from the cross between PI 256334 and HA89.

\section{Evaluation of the selected lines under several environments}

Field experiments were conducted in 2006 and 2007 to evaluate total seed tocopherol content in the selected lines IAST-306, IAST-413, IAST-522 and HA89 under different sowing dates. In 2006, an exceptionally low seed set was observed for IAST-522 at all sowing dates, which resulted in insufficient numbers of plants bearing seeds at each sowing date for the results to be representative. Accordingly, this line was removed from the study. The situation was similar for IAST-306 at the fifth and sixth sowing dates, i.e. 10 and 24 April. It is important to note that both sowing dates were out of the normal sowing time for sunflower in the area in which the experiment was conducted, which could have promoted the occurrence of self-incompatibility in this line despite selection being carried out for this trait. Seed tocopherol contents of the selected lines IAST-306 and IAST-413 and the control line HA89 sown at six dates are shown in Fig. 5. Total tocopherol content in IAST-413 seeds was consistently higher than that in HA89 seeds at all sowing dates, with the difference between both lines ranging from $146 \mathrm{mg} / \mathrm{kg}$ at sowing date 2 to $265 \mathrm{mg} / \mathrm{kg}$ at sowing date 3 . Total tocopherol content in IAST-306 seeds was very 


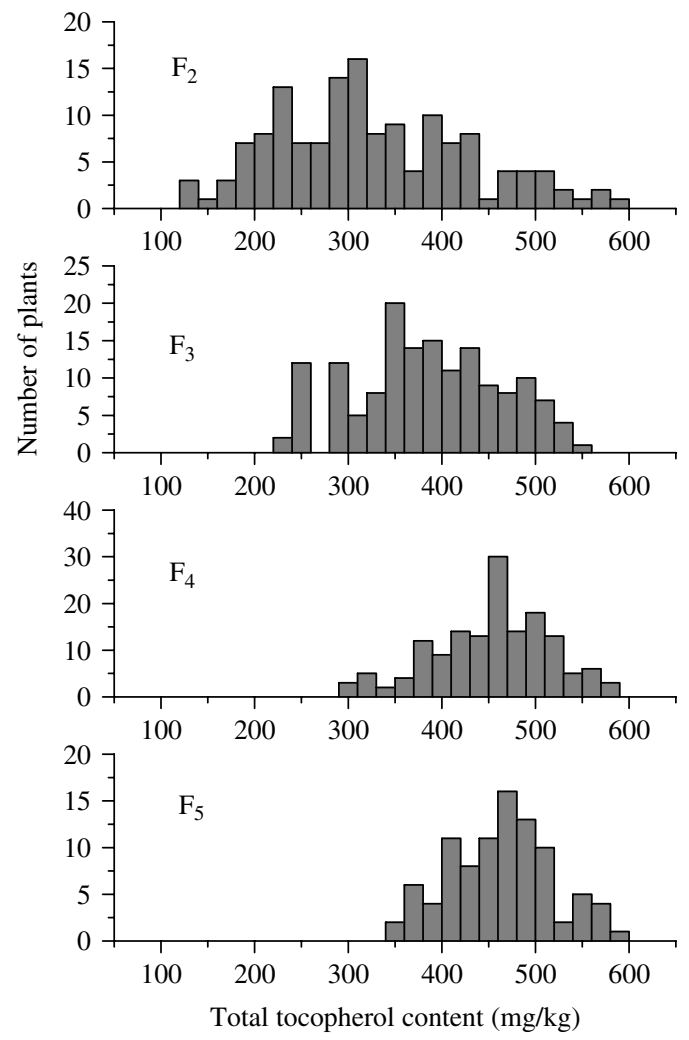

Fig. 4. Total tocopherol content in the $F_{2}$ through $F_{5}$ plant generations from the cross between the line HA89 and the germplasm accession PI 256334.

similar to that in IAST-413 in the four sowing dates for which seed of IAST-306 was obtained (Fig. 5).

In the field experiment conducted over eight sowing dates in 2007, data on tocopherol content were obtained in all cases except for the line IAST-413 in the last sowing date (11 June). The lines IAST-306 and IAST-413 had greater seed tocopherol content than HA89 at all sowing dates (Fig. 6). The difference in tocopherol content between IAST-306 and HA89 ranged from $141 \mathrm{mg} / \mathrm{kg}$ at sowing date 1 to $223 \mathrm{mg} / \mathrm{kg}$ at sowing date 4 , whereas the difference between IAST-413 and HA 89 ranged from $93 \mathrm{mg} / \mathrm{kg}$ at sowing date 7 to $256 \mathrm{mg} / \mathrm{kg}$ at sowing date 2 . The line IAST413 showed a higher tocopherol content than the line IAST-306 in the two first sowing dates, but from the fourth to the seventh sowing dates the tocopherol content of IAST-306 was greater, with a maximum difference of $109 \mathrm{mg} / \mathrm{kg}$ at the sixth sowing date.

\section{DISCUSSION}

The results of the present research indicate the existence of large variation for total tocopherol content in sunflower germplasm and demonstrate the feasibility of selecting for contrasting levels of tocopherols that are consistently expressed across environments.

It is important to note that the objective of the present research was not to identify environmental factors influencing tocopherol content or to evaluate genotype $\times$ environment effects, but to demonstrate that selected lines expressed the trait under a range of environments, thus discarding the conclusion that modified tocopherol levels were the result of a given environment. One line with reduced total tocopherol content and two lines with enhanced total tocopherol content were developed, in all three cases with alphatocopherol as the predominant tocopherol form $(>0 \cdot 9)$. Two accessions that contained increased proportions of beta- and gamma-tocopherol, respectively, have been reported elsewhere (Velasco et al. 2004). The environment considerably affected total tocopherol content in the three selected lines as well as in the control lines with standard tocopherol content, as revealed by the differences observed in different years and from different sowing dates within the same year, which is in agreement with previous reports on the large influence of the environment on this trait (Marquard 1990; Alpaslan \& Gündüz 2000; Velasco et al. 2002). Nevertheless, despite the environmental influence, increased tocopherol levels in the selected lines were consistently expressed across environments.

The line IAST-522, with reduced tocopherol content, did not perform well under the conditions of the field experiments conducted in 2006 and 2007, probably because of poor competition ability and self-incompatibility problems. Despite the fact that tocopherol content in this line could not be evaluated in the two field experiments, it showed a considerably lower tocopherol content than the check lines at all stages of selection, from the $S_{1}$ to the $S_{4}$ plant generations (Fig. 3). This clearly shows the underlying genetic control of low tocopherol content.

Self-incompatibility is a mechanism to promote insect-mediated cross-pollination that is present in wild sunflowers (Helianthus spp.) and open-pollinated populations and varieties of cultivated sunflower. It is controlled by one multiallelic locus (FernándezMartínez \& Knowles 1978). Modern breeding to promote heterosis through hybrids has been paralleled by selection for high levels of self-compatibility, but most of the accessions in germplasm collections usually show self-fertility barriers. This problem was particularly dramatic in the accession PI 256334, which produced virtually no seeds when self-fertilization was enforced, which was overcome by crossing to a self-fertile line and conducting simultaneous selection for self-fertility and high tocopherol content. 


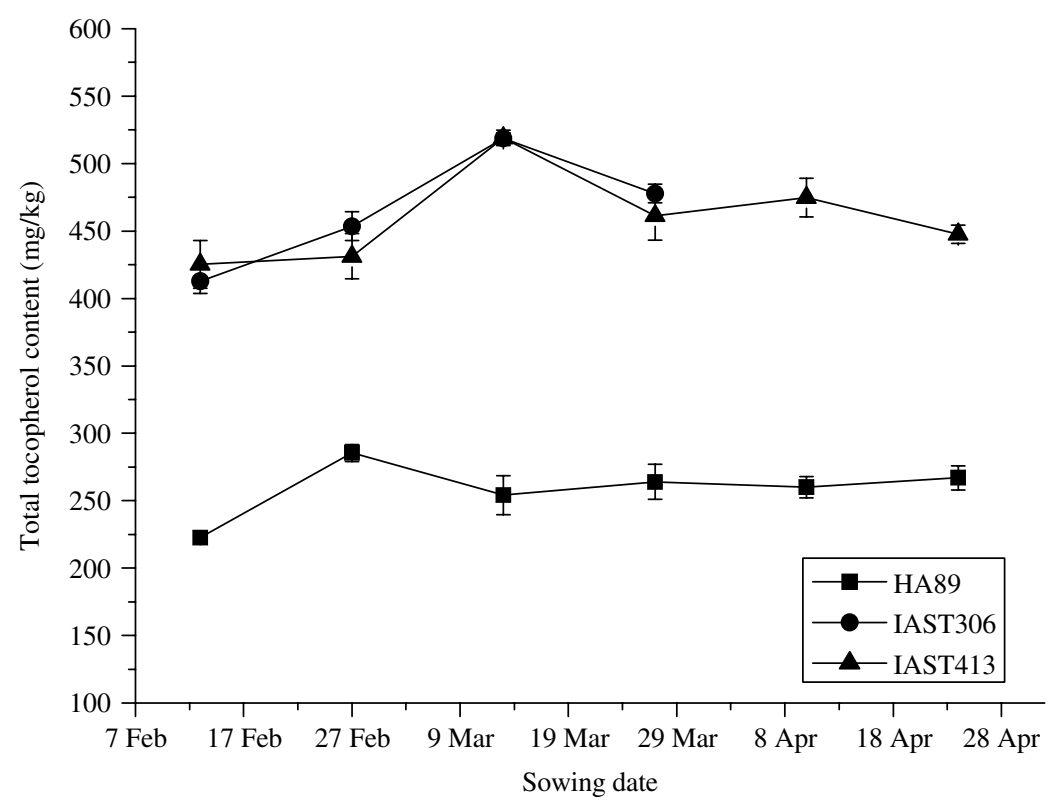

Fig. 5. Total seed tocopherol content in plants of the lines IAST-306 and IAST-413, selected for high total tocopherol content, and HA89, used as a check, grown in the field at Córdoba, Southern Spain in 2006, following six sowing dates.

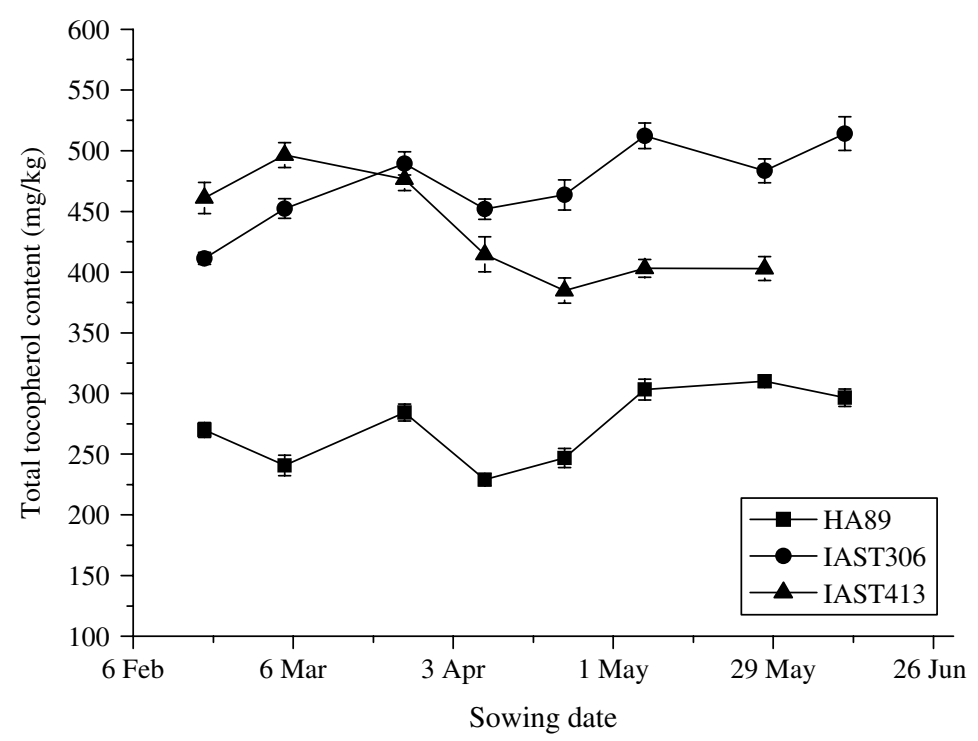

Fig. 6. Total seed tocopherol content in plants of the lines IAST-306 and IAST-413, selected for high total tocopherol content, and HA89, used as a check, grown in the field at Córdoba, Southern Spain in 2007, following eight sowing dates.

There are no studies on the inheritance of total tocopherol content in sunflower seeds, mainly because no genetic variation for such studies has been identified to date. The lines developed in the present research provide a valuable tool for studies on the inheritance of total tocopherol content in sunflower and for identifying genes involved in the accumulation of tocopherols in sunflower seeds. In rapeseed, Marwede et al. (2005) determined moderately large heritabilities for total tocopherol content, 
between 0.34 and $0 \cdot 48$. It is noteworthy that the increased tocopherol content initially detected in the self-incompatible accession PI 256334 was easily recovered after crosses with the self-fertile line HA89, with standard tocopherol content, which points to a moderate to high heritability of the increased tocopherol content in sunflower seeds. This point will need to be confirmed through detailed genetic studies.

Tocopherols are fat-soluble compounds that become an important part of the oil after its extraction from the seeds. The tocopherol concentration in the extracted oil is the most important trait from a commercial perspective. Despite the previous statement, the present study focused on the tocopherol concentration in the seeds and deliberately excluded tocopherol concentration in the oil from them. Tocopherols are synthesized in the plastids of photosynthetic organisms through a specific biosynthetic pathway that starts with the condensation of homogentisic acid and phytyl-diphosphate to form 2methyl-6-phytyl-1,4-benzoquinone, which is followed by subsequent ring methylation and ring cyclation steps (Dellapenna 2005). The biosynthesis of tocopherols is not related to the biosynthesis of fatty acids and triacylglycerols (reviewed in Somerville et al. 2000), which are the major components of the oil (>0.92; Åppelqvist 1989). A previous study revealed no correlation between seed oil and seed tocopherol content in sunflower seeds (Velasco et al. 2002). Accordingly, it is understood that the optimal breeding strategy to develop sunflower germplasm that produce a high tocopherol content in the oil is to identify and isolate germplasm carrying alleles that promote maximum tocopherol accumulation in the seeds and to introgress such genes into elite germplasm with high oil content.

The authors wish to thank Alberto Merino, Angustias Jiménez and Lucía Medina for their excellent technical assistance. The research was conducted within the research project AGL2004-01765 funded by the Spanish Ministry of Education and Science (MEC).

\section{REFERENCES}

Alpaslan, M. \& GündüZ, H. (2000). The effects of growing conditions on oil content, fatty acid composition and tocopherol content of some sunflower varieties produced in Turkey. Nahrung 44, 434-437.

ÅpPElqvist, L. A. (1989). The chemical nature of vegetable oils. In Oil Crops of the World (Eds G. Röbbelen, R. K. Downey \& A. Ashri), pp. 22-37. New York: McGrawHill.

Bramley, P. M., Elmadfa, I., Kafatos, A., Kelly, F. J., Manios, Y., Roxborough, H. E., Schuch, W., Sheehy, P. J. A. \& Wagner, K. H. (2000). Vitamin E. Journal of the Science of Food and Agriculture 80, 913-938.

Dellapenna, D. (2005). A decade of progress in understanding vitamin E synthesis in plants. Journal of Plant Physiology 162, 729-737.

Dolde, D., Vlahakis, C. \& Hazebroek, J. (1999). Tocopherols in breeding lines and effects of planting location, fatty acid composition, and temperature during development. Journal of the American Oil Chemists' Society 76, 349-355.

Fernández-Martínez， J. M. \& Knowles, P. F. (1978). Inheritance of self-incompatibility in wild sunflower. In Proceedings of the 8th International Sunflower Conference, Minneapolis, MN, USA, pp. 484 489. Paris, France: International Sunflower Association.

Goffman, F. D. \& Becker, H. C. (2001). Diallel analysis for tocopherol contents in seeds of rapeseed. Crop Science 41, 1072-1079.

Hofius, D. \& Sonnewald, U. (2003). Vitamin E biosynthesis: biochemistry meets cell biology. Trends in Plant Sciences 8, 6-8.

MARQuARD, R. (1990). Untersuchungen über dem Einfluss von Sorte und Standort auf den Tocopherolgehalt verschiedener Pflanzenöle. Fat Science and Technology 92, 452-455.
Marwede, V., Gül, M. K., Becker, H. C. \& Ecke, W. (2005). Mapping of QTL controlling tocopherol content in winter oilseed rape. Plant Breeding 124, 20-26.

Nolasco, S. M., Aguirrezábal, L. A. N. \& Crapiste, G. H. (2004). Tocopherol oil concentration in field-grown sunflower is accounted for by oil weight per seed. Journal of the American Oil Chemists' Society 81, 1045-1051.

Packer, L. \& Obermüller-Jevic, U. C. (2002). Vitamin E: an introduction. In The Antioxidants Vitamins $C$ and $E$ (Eds L. Packer, M. G. Traber, K. Kraemer \& B. Frei), pp. 133-151. Champaign, IL: AOCS Press.

Padley, F. B., Gunstone, F. D. \& Harwood, J. L. (1994). Occurrence and characteristics of oils and fats. In The Lipid Handbook (Eds F. D. Gunstone, J. L. Harwood \& F. B. Padley), pp. 47-223. London: Chapman and Hall.

Pongracz, G., Weiser, H. \& Matzinger, D. (1995). Tocopherole. Antioxidantien der Natur. Fat Science and Technology 97, 90-104.

Slack, C. R., Bertaud, W. S., Shaw, B. D., Holland, R., Browse, J. \& Wright, H. (1980). Some studies on the composition and surface properties of the oil bodies from oil seed cotyledons of safflower (Carthamus tinctorius) and linseed (Linum ustatissimum). Biochemical Journal 190, 551-561.

Somerville, C., Browse, J., Jaworski, J. G. \& Ohlrogge, J. B. (2000). Lipids. In Biochemistry and Molecular Biology of Plants (Eds B. B. Buchanan, W. Gruissem \& R. L. Jones), pp. 456-527. Rockville, MD: American Society of Plant Physiologists.

TAsan, M. \& Demirci, M. (2005). Total and individual tocopherol contents of sunflower oil at different steps of refining. European Food Research and Technology 220, 251-254.

THIES, W. (1997). Entwicklung von Ausgangsmaterial mit erhöhten alpha- oder gamma-Tocopherol-Gehalten im 
Samenöl für die Körnerraps-Züchtung. I. Quantitative Bestimmung der Tocopherole durch HPLC. Journal of Applied Botany 71, 62-67.

Velasco, L., Fernández-Martínez, J. M., García-Ruíz, R. \& Domínguez, J. (2002). Genetic and environmental variation for tocopherol content and composition in sunflower commercial hybrids. Journal of Agricultural Science, Cambridge 139, 425-429.

Velasco, L., Domínguez, J. \& Fernández-Martínez, J. M. (2004). Registration of T589 and T2100 sunflower germplasms with modified tocopherol profiles. Crop Science 44, 361-362. 